\title{
Rumbo a una nueva pneumatología
}

\section{Víctor Codina, S. J.}

\section{Contextualización histórica}

Desde mediados del siglo XX, se oyen voces en la Iglesia occidental latina que piden la elaboración de una teología del Espíritu Santo, que responda a las inquietudes personales, eclesiales y del mundo de hoy. Se constata un vacío pneumatológico, tanto en la teología sistemática como en la praxis pastoral, lo cual tiene consecuencias muy negativas para la vida de la Iglesia. La pneumatología es una asignatura pendiente. En la mayoría de facultades católicas de teología no existe un tratado específico de pneumatología.

El oriente cristiano nos ha acusado a los católicos occidentales de cristomonismo, es decir, de reducir la fe al misterio de Cristo, olvidando al Espíritu ${ }^{1}$, el cual parece estar en manos de la jerarquía y de unos cuantos místicos. Paul Evdokimov ha expresado con claridad las consecuencias del olvido pneumatólogico de occidente:

La ausencia de la economía del Espíritu Santo en la teología de los últimos siglos, como también su cristo-monismo, determinan que la libertad profética, la divinización de la humanidad, la dignidad adulta y regia del laicado y el nacimiento de la nueva criatura queden substituidos por la institución jerárquica de la Iglesia, planteada en términos de obediencia y sumisión ${ }^{2}$.

Uno de los textos más conocidos sobre la ausencia y la presencia del Espíritu en la vida cristiana es el del metropolita de Lataquia, más tarde patriarca de Antioquía, Ignacio Hazim. En un discurso, pronunciado en 1968, durante la

1. N. Nissiotis, "Pneumatologie orthodoxe", en Le Saint Sprit, pp. 85-105 (Genève: Labor et Fides, 1963). J. I. González Faus, en su libro Herejías del catolicismo actual, considera que una de estas herejías es el olvido del Espíritu Santo, pp. 117-131 (Madrid: Trotta, 2013).

2. P. Evdokimov, La connaissance de Dieu selon la tradition oriental, p. 146 (Lyon: Desclée de Brouwer, 1967). 
inauguración de la asamblea del Consejo Mundial de las Iglesias de Upsala, dijo lo siguiente:

Sin el Espíritu, Dios está lejos, Cristo permanece en el pasado, el evangelio es letra muerta, la Iglesia una simple organización, la autoridad un dominio, la misión una propaganda, el culto una evocación, el actuar cristiano una moral de esclavos.

Pero en Él, y en una sinergia indisociable, el cosmos es sostenido y gime en el alumbramiento del reino, el hombre está en lucha contra la carne, Cristo resucitado está aquí, el evangelio es fuente de vida, la Iglesia significa la comunión trinitaria, la autoridad es un servicio liberador, la misión es Pentecostés, la liturgia es memorial y anticipación, el actuar humano es divinizado ${ }^{3}$.

Por otra parte, la reforma del siglo XVI puede ser interpretada como un movimiento profético, suscitado por el Espíritu, que quería volver a las raíces evangélicas de la Iglesia. Aunque luego, por falta de diálogo, por incompetencia y por culpa de ambas partes, el movimiento acabara en ruptura. Toda la santidad y riqueza espiritual de las iglesias de la reforma es fruto del Espíritu. Asimismo, la teología de la reforma moderna es muy sensible al tercer artículo del Credo. Basta con citar los nombres de Karl Barh y Jürgen Moltmann.

El déficit pneumatológico de la Iglesia católica, reforzado por las rupturas del oriente y de la reforma, ha empobrecido notablemente a la Iglesia católica. En la práctica, esta ha intentado compensar la ausencia de pneumatología con una serie de sucedáneos del Espíritu. Y. M. Congar no duda en hablar de los vacíos del Espíritu de la Iglesia latina, los cuales han sido suplidos con otros elementos teológicos, en concreto, por el papa, María y la eucaristía ${ }^{4}$.

Estas tres realidades son irrenunciables para nuestra fe, pero deben ser situadas dentro de la jerarquía de verdades y en conexión con el Espíritu. Al margen de él, fácilmente se distorsionan y se convierten en papolatría, en mariolatría y en una teología de la eucaristía más centrada en la presencia real, el sacrificio y la adoración que en la celebración y la comunión. Más aún, muchas veces estos sucedáneos se utilizan como armas arrojadizas antiprotestantes.

En cambio, desde la pneumatología, el papa, más que vicario de Cristo, es el vicario de Pedro, ya que quien hace las veces de Cristo es el Espíritu, y es servidor de los siervos de Dios; María es icono y templo del Espíritu; y la eucaristía se comprende a la luz de la epíclesis y la comunión con el Señor resucitado por el Espíritu, y va más allá del precepto dominical y de la obligación de comulgar por la pascua...

3. I. Hazim, "La Résurrection et l'homme d'aujourd'hui", Irénikon 42 (1968), 344-359.

4. Y. M. Congar, El Espíritu Santo, pp. 188-194 (Barcelona: Herder, 1982). 
Más aún, podemos preguntarnos si la explosión carismática y pentecostal, que se vive hoy en numerosos sectores de las iglesias, puede ser interpretada solo como una reacción ante la ausencia de una pneumatología en la Iglesia oficial, o si también puede ser considerada como un verdadero signo de los tiempos, que debemos discernir. Indudablemente, el concilio Vaticano II respondió, en parte, a esta preocupación por la ausencia de una pneumatología ( $L G 4)$. Pero aun así, después del concilio, Pablo VI hizo una profética advertencia sobre la necesidad de la pneumatología:

A la cristología y eclesiología del concilio, debe suceder un estudio nuevo y un culto nuevo del Espíritu Santo, justamente como necesario complemento de la doctrina conciliars.

La demanda generalizada de pneumatología ha recibido diversas respuestas teológicas por parte de los teólogos, fundamentalmente de europeos y estadounidenses. Estos teólogos han hecho aportes valiosos - la relación entre el Espíritu y la experiencia espiritual, el Espíritu y la cristología mesiánica, el Espíritu y la Iglesia-, que incorporan la riqueza de la pneumatología del oriente cristiano. De esa manera, la teología se ha abierto a los nuevos desafíos de la sociedad actual, pero no es especialmente sensible al tema de los pobres ${ }^{6}$.

\section{La postura latinoamericana}

En una declaración un tanto sorprendente, el actual prefecto de la Congregación para la Doctrina de la fe, Gerhard Ludwig Müller, afirma que "el movimiento eclesial y teológico que después del concilio Vaticano II halló eco en todo el mundo bajo el nombre de 'teología de la liberación', es una de las corrientes más significativas de la teología católica del siglo XX"7.

La teología de la liberación, que nace en América Latina, en las décadas de 1970 y 1980, como acto segundo, presupone la existencia de una irrupción de los pobres en la sociedad y la Iglesia. Esta irrupción se ha ido plasmando en una serie de acontecimientos y hechos novedosos, como las asambleas de Medellín y Puebla; los obispos que se han erigido en verdaderos santos padres de la Iglesia de los pobres; la vida religiosa inserta en medios populares; el surgimiento de las comunidades eclesiales de base; los cristianos comprometidos tanto con

5. Pablo VI, Audiencia general del 6 de junio de 1973, en Enseñanzas al pueblo de Dios, XI (1973), 74. Esta afirmación es citada en la encíclica de Juan Pablo II sobre el Espíritu (Dominum et vivificantem, 1986, $\mathrm{N}^{\circ} 2$ ).

6. Cfr. V. Codina, El Espíritu del Señor actúa desde abajo, pp. 140-143 (Santander: Sal Terrae, 2015).

7. G. L. Müller, "Experiencia liberadora: impulsos para la teología europea", en G. Gutiérrez y G. L. Müller, Del lado de los pobres. Teología de la liberación, p. 29 (Madrid: San Pablo, 2013). 
la sociedad como con la Iglesia; y, finalmente, la aparición de mártires por la justicia del evangelio.

La teología de la liberación formula su novedad teológica en una doble línea: el seguimiento del Jesús de Nazaret histórico y la opción por los pobres. Esto da a la teología de la liberación carta de ciudadanía eclesial, más allá de posibles exageraciones o ambigüedades. Lógicamente, esta teología ha desarrollado una cristología desde América Latina, una eclesiología de la Iglesia de los pobres, una metodología del ver, juzgar y actuar, las llamadas mediaciones socio-analíticas, hermenéuticas y prácticas. Además, ha abordado otros temas, como la moral, la escatología, los sacramentos, la imagen de Dios y la Trinidad, la lectura orante de la Escritura e incluso una espiritualidad liberadora - por ejemplo, Beber en su propio pozo, de G. Gutiérrez.

Sin embargo, en sus primeros años, no desarrolla una auténtica pneumatología, seguramente, por influjo del cristo-monismo imperante en occidente, lo cual ha tenido efectos negativos: un cierto voluntarismo, demasiado empeñado en el cambio de estructuras y en el compromiso político; una visión excesivamente ética de la vida cristiana, con riesgo de olvidar la gratuidad y el misterio de la cruz; una espiritualidad que descuida el cambio del corazón humano; un paternalismo hacia los pobres; una cierta tendencia milenarista, muy ligada a la utopía de una próxima sociedad socialista; un mesianismo y una imagen del reino que tiene el peligro de ser demasiado terrestre; la confusión entre la fuerza teológica de los pobres y su fuerza política e histórica; la ideologización de los pobres; la satanización de los adversarios, etc. Ha habido crisis personales, rupturas internas, desánimos, abandonos y desilusión, al constatar que la realidad es reacia al cambio...

Por eso, de forma lenta, pero progresiva, se ha constatado este déficit pneumatológico y se ha comenzado a ver en la irrupción de los pobres y en el nuevo caminar de la sociedad y de la Iglesia latinoamericana, una auténtica irrupción del Espíritu, un kairós. Los obispos, reunidos en Puebla, ya afirmaban:

El Espíritu que llenó el orbe de la tierra, abarcó también lo que había de bueno en las culturas precolombinas; él mismo las ayudó a recibir el evangelio; él sigue hoy suscitando anhelos de salvación liberadora en nuestros pueblos. Se hace por tanto necesario, descubrir su presencia auténtica en la historia del continente ${ }^{8}$.

Así, lentamente, la teología de la liberación se ha abierto a la presencia del Espíritu, actuante en el clamor de los pobres y en su anhelo de liberación. Poco a poco, ha ido surgiendo una pneumatología latinoamericana, gracias a los trabajos de J. Comblin, L. Boff, D. Irarrázaval, María José Caram, María Clara Luccheti

8. Puebla, 201. 
de Bingemer, entre otros ${ }^{9}$. Superado el riesgo del cristo-monismo, la teología de la liberación puede ofrecer un rico aporte a la pneumatología.

\section{El tercer artículo del Credo}

Indudablemente, una pneumatología se ha de construir desde una base bíblica, ya que el Espíritu del Señor llena el universo (Sab 1,7). Desde el Génesis hasta el Apocalipsis, el Espíritu está presente, en toda la historia de la salvación. Sin embargo, la teología sistemática debe partir de los datos dogmáticos ya existentes, comenzando por el credo del concilio de Constantinopla I, cuyo artículo tercero está dedicado al Espíritu Santo.

La Iglesia primitiva, tal como lo atestiguan los textos bíblicos y los documentos históricos sobre la vida eclesial de los orígenes, no dudó creer en el Espíritu Santo, ni profesar su fe trinitaria, en la liturgia bautismal, en la epíclesis de los sacramentos y en sus doxologías, aun cuando esta fe no fuera muy refleja, ni tuviera muchas explicitaciones teológicas. La Iglesia bautizaba en el nombre del Padre, del Hijo y del Espíritu Santo, tal como se refleja en Mateo 28,19, y aceptaba carismas y profecías como dones del Espíritu.

Pero pronto comenzaron las herejías cristológicas y trinitarias, en concreto, el arrianismo, que negaba la divinidad del Hijo y su consubstancialidad con el Padre. El concilio de Nicea (325), convocado por Constantino, proclamó la divinidad del Hijo y su consubstancialidad con el Padre (homoousios). En su credo se añadió una breve afirmación de fe en el Espíritu Santo, la cual no desarrolló.

Después de Nicea, la corriente arriana se empeñó en negar la divinidad del Espíritu. El Espíritu sería una criatura excelsa, creada por el Hijo, acaso una energía o un ángel, pero no de la misma naturaleza del Padre, ni del Hijo. Por tanto, no Dios, ni objeto de adoración. Eran los llamados pneumatómacos, trópicos y también macedonios.

Una serie de obispos y de padres de la Iglesia, como Atanasio, Basilio, Gregorio Nacianceno, Gregorio de Nisa, Cirilo de Jerusalén, etc., reaccionaron ante esta nueva herejía y defendieron la divinidad del Espíritu. Es interesante constatar que algunos de los argumentos esgrimidos por los defensores de la divinidad del Espíritu provenían de la misma vida de la Iglesia, de la praxis eclesial. Cirilo, en sus catequesis bautismales, presenta la fe de la Iglesia en la divinidad del Espíritu, desde la praxis litúrgica del bautismo y de la epíclesis. Otros, como Atanasio, argumentaban que si el Espíritu Santo no fuera Dios, no podríamos ser divinizados. También impactaba el fenómeno del monacato, como

9. Cfr. V. Codina, El Espíritu del Señor actúa desde abajo, o. c., pp. 175-181. 
movimiento profético y crítico, suscitado por el Espíritu. Por tanto, tenía que provenir de Dios.

Pero seguramente Basilio, en su tratado Sobre el Espíritu Santo, fue el más lúcido y el que preparó el terreno para el concilio de Constantinopla I. Basilio afirma que en la doxología trinitaria se puede afirmar "gloria al Padre con el Hijo y con el Espíritu Santo" y "gloria al Padre por medio del Hijo, en el Espíritu Santo"10. Aunque no emplea la fórmula consubstancial (homoousios), ni dice explícitamente que el Espíritu sea Dios, confiesa que el Espíritu recibe el mismo honor y gloria (homotimon) que el Padre y el Hijo, y está unido por comunidad de naturaleza con el Padre y el Hijo, tal como aparece en la liturgia bautismal.

En este contexto se celebra el concilio de Constantinopla, convocado por el emperador Teodosio (381). El concilio se desarrolla en medio de tensiones eclesiológicas entre Roma y Constantinopla y de tensiones teológicas entre Antioquia y Alejandría ${ }^{11}$. Aquí interesa destacar el tercer artículo del Credo, que completa el de Nicea, que solo afirmaba la fe en el Espíritu Santo. Intentaremos glosar sus afirmaciones e iluminarlas desde el progreso y la evolución dogmática, así como desde los signos de los tiempos, en concreto, desde la perspectiva liberadora de América Latina.

"Creo...", es decir, estamos ante un acto de fe, no ante una mera disquisición racional o una opinión cultural sometida a las vicisitudes del tiempo ${ }^{12}$. " $Y$ en el Espiritu Santo", es decir, fe en un Espíritu que es santo y fuente de santificación, y que puede santificar y divinizar a los fieles. Al acto de fe en Dios Padre todopoderoso y en un solo Señor Jesucristo, se añade la fe en el Espíritu Santo. El tercer artículo del Credo forma parte de nuestra fe trinitaria.

"Señor", es decir, Kyrios, de categoría divina, no subordinado, ni esclavo. Frente a tantos poderes humanos que se divinizan y encumbran, frente a tantas idolatrías de sistemas económicos y políticos, se proclama que el Espíritu es Señor y Dios. Es decir, no se trata de cualquier espíritu humano, filosófico, cultural, hegeliano, ni tampoco del espíritu del tiempo (Zeitgeist), sino de un Espíritu divino. De aquí surge ya la necesidad del discernimiento espiritual, para discernir si un espíritu es Espíritu santo o no lo es.

"Vivificante", es decir, dador de vida. Es el Espíritu creador de vida (Jn 67,63; 2 Cor 3,6), al que invoca el himno medieval Veni Creator Spiritus.

10. Basilio, El Espiritu Santo, 1, 3.

11. Cfr. H. Jedin, Breve historia de los concilios, pp. 27-32 (Barcelona: Herder, 1963); K. Schatz, Los concilios ecuménicos: encrucijadas de la historia, pp. $43-47$ (Madrid: Trotta, 1999); C. Granado, El Espíritu Santo en los santos padres, pp. 175-182 (Madrid: San Pablo, 2013).

12. DH 150. Seguimos la traducción castellana del texto griego. 
Desde aquí, podemos entablar una estrecha relación entre el Espíritu y la creación, entre Espíritu y ecología, en la dirección de la Laudato si'13. Es dador de vida (en griego, zoopoion), de una vida que no es meramente natural (bios), sino divina (zoe). Estamos ante el fundamento de la divinización del cristiano, un tema muy querido por el oriente cristiano. Desde nuestro momento histórico actual, habría que añadir que la divinización no es alienación, sino principio de humanización. Desde América Latina, se señala que esta vida divina presupone una vida humana digna, comenzando por lo mínimo: el pan de cada día. Las tres mínimas exigencias de todo pueblo: techo, trabajo y tierra. Además, este Espíritu vivificante es el Espíritu consolador, que anima y consuela al pueblo pobre, en sus luchas por una vida más digna.

Consiguientemente, podemos tener la certeza de que todo lo bueno, lo positivo, lo humano, lo noble y lo conforme con la creación y la naturaleza, proviene del Espíritu creador de vida. La historia está dinamizada por una energía vital divina, que todo lo orienta hacia la plenitud de vida, hacia lo que se llama el reino. Esto es fuente de esperanza, sobre todo, para los crucificados de la historia. Por otra parte, no podemos olvidar que en Génesis 1,2, el Espíritu (ruah) aletea desde el caos, un dato de su acción, confirmada a lo largo de la historia. Esta característica es muy importante para una pneumatología desde América Latina y es un aporte a la pneumatología de toda la Iglesia: el Espíritu actúa desde abajo, desde el tohu wabohu de la historia. También conviene subrayar, como insinúan las teólogas, que ruah es femenino y que existe una cierta connaturalidad entre el Espíritu que genera vida y la mujer, tal como lo ha desarrollado la Iglesia de Siria.

$\mathrm{Al}$ confesar "que procede del Padre", afirmamos que no es criatura, ni una emanación de la sustancia divina, ni tampoco es engendrado como el Hijo, sino que es una persona frente al Padre. El símbolo del concilio de Constantinopla afirma que el Espíritu procede del Padre, sin citar al Hijo. Esta es la fe común de occidente y oriente. Quien añada o quite algo a esa profesión de fe es considerado anatema.

El tercer sínodo de Toledo (España), reunido en 589, reacciona contra el arrianismo, que negaba la consubstancialidad del Hijo con el Padre. De esa manera, muestra la divinidad del Hijo al condenar a quien no afirme que el Espíritu procede del Padre y del Hijo (filioque). Si el Espíritu procede tanto del Padre como del Hijo, es evidente que el Hijo es de la misma esencia divina que el Padre. El filioque se extiende a Francia, Alemania e Italia, a pesar de la oposición de Roma. En 1014, cuando el emperador germánico Enrique II es coronado por Benedicto VIII, Roma introduce en el credo, por primera vez, el filioque.

13. Cfr. L. Boff, O Spirito Santo: fogo interior doador de vida e Pai dos pobres (Petrópolis: Vozes, 2013). 
Más tarde, en 1054, el cardenal Humberto de Silva Cándida, delegado del papa, en el decreto de excomunión, colocado sobre el altar de Santa Sofía de Constantinopla, reprocha al oriente, entre otras cosas, la omisión del filioque en el credo. Oriente lo rechaza, porque rompe el modo ternario de las relaciones trinitarias, y porque establece una relación dual de filiación entre el Padre y el Hijo, como principio espirador de quien procede el Espíritu Santo. La monarquía absoluta del Padre queda negada, al ser compartida por el Hijo, en la procesión del Espíritu, y este queda relegado a un tercer lugar apendicular.

La pneumatología occidental ha desarrollado, de manera especial, la línea de Juan, según la cual el Espíritu brota del crucificado-resucitado (Jn 19,31-34; 20,21.23), pues antes de la pascua no se comunicaba el Espíritu $($ Jn 7,39). De ahí que no tenga tan en cuenta la pneumatología del Antiguo Testamento ni la de Lucas, donde el Espíritu prepara los caminos del Señor.

Creemos que existe una estrecha relación entre la introducción del filioque en el credo y el cristo-monismo occidental, con todas sus consecuencias negativas de centralismo, legalismo, clericalismo, etc. Tomás de Aquino, que vive en una atmósfera a favor del filioque, afirma claramente que hay una relación estrecha entre la negación de este, por parte de oriente, y la negación del primado de la Iglesia universal al vicario de Cristo ${ }^{14}$. Detrás de esta afirmación subyace la convicción de que el vicario de Cristo es la causa instrumental de la donación del Espíritu en la Iglesia.

Movido por el interés en el diálogo ecuménico y conciliatorio, Paul Evdokimov propone que el concepto del filioque se equilibre y complete con el del spirituque, es decir, que el Hijo es engendrado por el Padre y el Espíritu. Algo sugerido por la misma economía de la salvación, cuando afirma que Jesús nace por obra del Espíritu, que el Espíritu desciende sobre Cristo en la epifanía bautismal y que el Espíritu es quien engendra a Cristo en los fieles ${ }^{15}$.

El teólogo católico F. X. Durrwell ${ }^{16}$, para quien el Espíritu es como el seno del Padre, de donde el Hijo es amorosamente engendrado, también acepta el spirituque. El Espíritu desempeña así una función casi maternal, en el engendramiento del Hijo, tal como afirma el XI concilio de Toledo, en $675^{17}$. El teólogo ortodoxo Bobriskoy, que acepta el spirituque de Evdokimov, reconoce que la Iglesia siempre osciló entre el esquema Padre-Hijo-Espíritu y Padre-Espíritu-Hijo ${ }^{18}$.

14. "Contra errores Graecorum", en Opera Omnia, ed. Parma t XV, 256.

15. P. Evdokimov, Présence de l'Esprit Sant dans la tradition ortohodoxe, pp. 77-78 (París: Editions du Cerf, 2011).

16. F. X. Durrwell, Nuestro Padre, p. 142 (Salamanca: Sígueme, 1990).

17. De patris utero, id est de substantia eius, idem Filius genitus vel natus, DS 526.

18. B. Bobriskoy, El misterio de la Trinidad, p. 87 (Salamanca: Sígueme, 2008). 
Al confesar "que con el Padre y el Hijo, reciben una misma adoración y gloria", se afirma que es conjuntamente adorado y glorificado y que recibe el mismo honor y gloria, tal como aparece en la doxología de la liturgia eclesial. Esta es una forma de repetir la dignidad divina del Espíritu y de reafirmar la dimensión comunitaria de la Trinidad, fuente de toda comunión y comunidad cristiana y humana. En ese sentido, las asambleas de las comunidades de base latinoamericanas confiesan que "la Trinidad es la mejor comunidad".

Después de describir la dimensión intratrinitaria del Espíritu, el Credo pasa a su acción ad extra en la historia de la salvación, donde está presente y actúa. Así, declara "y que habló por los profetas". Es notable la estrecha conexión entre profetismo y Espíritu, la cual vale, ciertamente, para los profetas del Antiguo Testamento, que preparan el camino del Señor Jesús, pero también vale para la Iglesia y para la toda la historia, que el Espíritu orienta al reino de Dios. Aquí, el Espíritu no aparece directamente ligado al elemento estructural y jerárquico, sino a la vida del pueblo, a los carismas y dones que concede a quien quiere y como quiere.

Desde América Latina, hay que rescatar que el Espíritu profético es el que unge a los profetas de Israel y los lanza a la misión de proclamar el derecho y la justicia, mispat sedaqah, en favor de los pobres y desvalidos. Frente a la tendencia a reducir la acción del Espíritu a la interioridad de sus dones, los siete dones, hay que recuperar esta dimensión social y su relación con la nueva creación, tal como aparece en Isaías 11,1-9. Reducir el Espíritu a "dulce huésped del alma" es empobrecer su dimensión profética. Habría que recuperar la afirmación medieval de que el Espíritu es "el padre de los pobres". Asimismo, desde esta óptica profética del Espíritu, se puede recuperar su acción en los profetas sociales, culturales y religiosos, en los filósofos y artistas, así como en todos aquellos que colaboran con el bien de la humanidad.

"Y en la Iglesia, una, santa, católica y apostólica". Curiosamente, la Iglesia no se asocia al segundo artículo cristológico del Credo, sino al tercer artículo pneumatológico, y tampoco como fe en una especie de cuarta persona trinitaria, sino como fruto de la fe en el Espíritu, junto con otros efectos que se citan a continuación. Es una afirmación del origen pascual-pentecostal de la Iglesia, que rompe el esquema clásico, que vincula al Jesús histórico con la fundación de la Iglesia. Según el teólogo Ratzinger, la Iglesia no nace en Belén, sino en la Jerusalén pascual. Aquí se afirma, por tanto, que el Espíritu es la fuente de la unidad, de la santidad, de la catolicidad y de la apostolicidad de la Iglesia.

Frente a las divisiones eclesiales de la historia, frente a sus escándalos y pecados pasados y actuales, frente a los particularismos y las inercias apostólicas y misioneras, frente a los que parecen identificar a la Iglesia con sus estamentos organizativos y de poder, el Credo invita a creer en la presencia viva y actuante del Espíritu en la Iglesia. La Iglesia es el lugar donde florece el Espíritu del 
Señor, su sacramento, aunque la desborda y nadie queda excluido de su acción. La Iglesia no tiene el monopolio del Espíritu y de la salvación, sino que solo es el sacramento de salvación ( $L G 1,9,48)$. Desde América Latina, el Espíritu profético lanza a la Iglesia a ser Iglesia de la justicia e Iglesia de los pobres, de los pequeños y excluidos. No es un espíritu del poder y de la ostentación, no es davídico, sino nazareno. Este Espíritu anima a las comunidades de base y a los grupos populares a leer el evangelio y a comprometerse en la lucha por un mundo mejor y por edificar una Iglesia nazarena, samaritana, profética, santuario y casa del pueblo.

"Reconocemos un solo bautismo para la remisión de los pecados". Por una parte, afirma la dimensión sacramental de la Iglesia, y, por otra, que el Espíritu es el que, a través del bautismo, perdona los pecados, como aparece en los textos pascuales (Jn 20,21-23) y de los Hechos de los apóstoles (2,37-41). En la Iglesia hay esperanza de perdón y misericordia, para superar la experiencia de pecado. En este proceso sacramental del perdón, el ministro no posee poderes mágicos, sino que es un simple instrumento del Espíritu misericordioso y perdonador.

" $Y$ esperamos la resurrección de los muertos". Si el pecado desanima, la amenaza de la muerte asusta. Por eso, el Espíritu es fuente de esperanza, en la medida en que nos hace pasar de la muerte a la vida y nos promete la resurrección. Cabe recordar aquí el texto de Ezequiel que habla del campo de huesos, que el Espíritu hace revivir (Ez 37), y al Espíritu que resucitó a Jesús de entre los muertos y que nos resucitará a nosotros (Rom 8,11). El Espíritu vivificador no solo hace pasar del caos y del no ser al ser, sino que también de la muerte a la vida. Desde América Latina, hemos de retomar el éxodo y el proceso liberador del Espíritu, que actúa desde abajo, desde el de profundis de la historia, desde los pobres, los pequeños y los olvidados. El Espíritu clama desde los pobres. El Espíritu es fuente de verdadera esperanza.

"Y la vida del mundo futuro". Esta afirmación escatológica está estrechamente relacionada con la anterior. Pero hemos de añadir, desde América Latina, que la vida futura ya comienza aquí, que el Espíritu escatológico de lo definitivo se hace presente y guía nuestra historia personal y colectiva. Él nos impulsa a transfigurar este mundo (GS 39) y se manifiesta en los deseos más profundos de la humanidad, en los llamados signos de los tiempos (GS 4,11, 44), los cuales hemos de discernir continuamente. ¿Cómo discernir los diversos espíritus que nos rodean? ¿Qué criterio hemos de tener para juzgar sin equivocarnos? Aquí hay que acudir a Jesús.

Por eso, además de las atribuciones que el tercer artículo del Credo otorga al Espíritu, conviene añadir una referencia a su acción, presente en el segundo artículo cristológico. Sin esta referencia a Jesucristo, se correría el riesgo de desembocar en un pneumato-monismo. Creo en un solo Señor Jesucristo que "por obra del Espíritu Santo, se encarnó de María virgen y se hizo hombre". 
Aquí aparece otra dimensión del Espíritu, vinculada a la encarnación de Jesús: el Espíritu que habló por los profetas, anunciando al Mesías futuro, realiza el misterio de la encarnación de Jesús en nuestra historia, en el seno de María.

Así, la pneumatología joanea se complementa con la lucana. El Espíritu prepara los caminos del Señor, hace posible su encarnación, lo unge en el bautismo, lo guía al desierto, lo lleva a proclamar su mensaje de buena nueva a los pobres en Nazaret, y por él hace milagros y señala que el reino de Dios ya ha llegado. Este Espíritu es el que, en Pentecostés, hace nacer la Iglesia y la guía en la historia, como aparece en los Hechos de los apóstoles. Basilio lo expresó magistralmente:

La venida de Cristo, el Espíritu la precede. La encarnación: de ella es inseparable el Espíritu. Las acciones milagrosas, los carismas de curación, se dan por medio del Espíritu. El diablo es rechazado ante la presencia del Espíritu. La redención de los pecados se da en la gracia del Espíritu" ${ }^{19}$.

De este modo, se profesa la fe en las dos misiones del Padre: la misión del Hijo y la del Espíritu. Ellos son los dos brazos del Padre, en expresión clásica de Ireneo de Lyon. Ambos tienen funciones diferentes, pero armónicas y complementarias ${ }^{20}$. El Hijo se encarna en Jesús de Nazaret, en tiempos de César Augusto, es la Palabra; mientras que el Espíritu no se encarna en nadie, es silencioso y anónimo, pero mueve desde dentro a personas, comunidades y grupos muy diversos hacia Jesús y el reino. En Jesús se disciernen los espíritus. Un espíritu que lo maldiga, que no siga su estilo de vida de Nazaret, de pobreza y sencillez, que no sea solidario con los pobres, que niegue la cruz, no es el Espíritu de Jesús. Desde América Latina, se acentúa que el Espíritu es nazareno, samaritano y padre de los pobres y sencillos, que actúa desde abajo. El filioque necesita la complementación del spirituque. Desde aquí, se puede elaborar tanto una cristología pneumática como una pneumatología cristológica, tal como ya se ha comenzado a hacer, aunque no siempre con sensibilidad hacia los pobres y la justicia.

\section{Conclusión}

Hemos de pasar del cristo-monismo filioquista a una pneumatología, que incorpore tanto la visión de Juan como la de Lucas (spirituque), que confiese las dos misiones del Padre y que, desde América Latina, afirme claramente que el Espíritu de Jesús, que todo lo llena, actúa desde abajo, desde el clamor de los pobres y los pequeños, desde la noche y el caos, siempre para engendrar vida, la vida de cada día y la vida eterna. Es necesario elaborar una pneumatología

19. Basilio, El Espíritu Santo, 16, 39.

20. Ireneo, Adversus haereses, IV, 7, 4. 
nazarena y samaritana, más femenina, más popular, más interreligiosa y misionera, más holística, en la línea del papa Francisco. Acabemos con un texto suyo:

Para mantener vivo el ardor misionero hace falta una decidida confianza en el Espíritu Santo, porque Él viene en ayuda de nuestra debilidad (Rom 8,26). Pero esta confianza generosa tiene que alimentarse y para esto necesitamos invocarlo incesantemente. Él puede sanar todo lo que nos debilita en el empeño misionero. Es verdad que esta confianza en lo invisible puede producirnos cierto vértigo, es como sumergirse en un mar donde no sabemos qué vamos a encontrar. Yo mismo lo experimenté tantas veces. Pero no hay mayor libertad que la de dejarse llevar por el Espíritu, renunciar a calcularlo todo y a controlarlo todo, y permitir que Él nos ilumine, nos guíe, nos oriente, nos impulse hacia donde Él quiera.

Él sabe bien lo que hace falta en cada época y en cada momento. ¡Esto se llama ser misteriosamente fecundos! ( $E G$ 280)

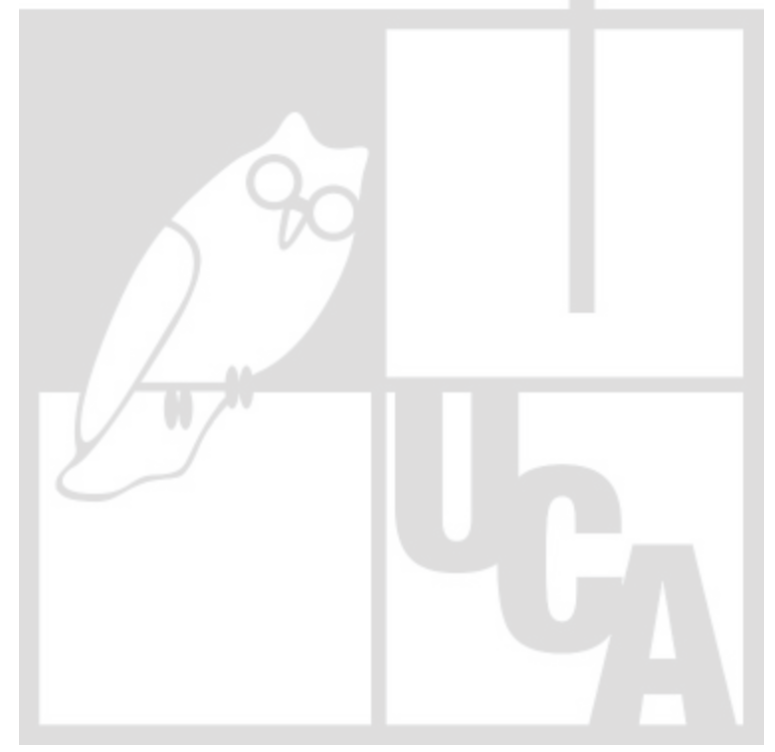

